\title{
Co-evolution of Earth systems during the Devonian Period
}

\author{
THOMAS J. AlGEO ${ }^{1,2}$ \\ ${ }^{1}$ Department of Geology, University of Cincinnati, \\ Cincinnati, Ohio, U.S.A. \\ ${ }^{2}$ State Key Laboratories of GPMR and BGEG, China \\ University of Geosciences, Wuhan, China
}

The spread of higher land plants during the Devonian Period (419-359 million years ago) transformed continental surface environments and triggered major changes in Earth climate. A rapid diversification of early land plants during the latter part of the Early Devonian (Pragian-Emsian stages) coincided with a strong cooling trend (documented by conodont $\delta^{18} \mathrm{O}$ ) and a major expansion of marine anoxia (documented by carbonate $\delta^{238} \mathrm{U}$ ). This pattern reflects massive organic carbon burial and atmospheric $\mathrm{CO}_{2}$ drawdown related to intensified chemical weathering and nutrient fluxes to the ocean. A second milestone was the origin of trees and the appearance of the first forests during the late Middle Devonian (Givetian). Secular variation in the carbon-isotopic composition of vascular land plants, reflecting a transient rise in atmospheric $\mathrm{pCO}_{2}$, coincided with climatic warming at that time. This $\sim 5-$ million-year-long event interrupted the long-term trend of falling $\mathrm{pCO}_{2}$ and global cooling linked to plantinduced enhancement of silicate weathering that characterized most of the Devonian. It was triggered by the rapid spread of closed-canopy forests, which reduced Earth-surface albedo and intensified evapotranspiration in the forest understory, leading to a transient surface warming and enhancement of soil organic matter recycling. Thus, the spread of vascular land plants during the Devonian led to both warming and cooling trends, depending on the nature of floral community changes and the specifics of vegetationclimate feedbacks. The uranium- and carbon-isotopic records to be presented in this talk provide some of the first high-resolution links between land-plant evolution and contemporaneous marine environmental changes. 